\title{
Spatio-temporal Evolution of the Australian Lithosphere- Asthenosphere Boundary from Mafic Volcanism
}

\author{
M. KLÖCKING ${ }^{1}$, K. CZARNOTA ${ }^{2}$, P.W. BALL ${ }^{1}$, D.C. \\ CHAMPION $^{2}$, D.R. DAVIES ${ }^{1}$ \\ ${ }^{1}$ Research School of Earth Sciences, Australian National \\ University, Canberra, ACT, Australia; \\ marthe.kloecking@anu.edu.au \\ ${ }^{2}$ Geoscience Australia, Canberra, ACT, Australia
}

Cratonic margins host the natural resources upon which our society depends. Despite this significance, little is known about the dynamical evolution of these regions and the stability of substantial steps in plate thickness that delineate their boundaries with adjacent mantle. Here, we investigate the spatio-temporal evolution of Australian cratonic lithosphere and underlying asthenospheric mantle by utilising the geochemical composition of mafic volcanic rocks preserved throughout the continent's history. We have collated a large database of mafic volcanic and shallow intrusive samples that was screened to remove data affected by crystal fractionation or assimilation of cumulate material. We use forward and inverse modelling of volcanic trace element compositions to calculate the depth and extent of melting for 28 distinct igneous provinces in the North Australian craton. Multiple distinct melting models are employed to fully explore parameter space and the associated uncertainties. These results are then used to infer mantle potential temperature and lithospheric thickness at the time of eruption. The majority of Paleoproterozoic igneous events record high mantle potential temperatures of $1350-1450{ }^{\circ} \mathrm{C}$ and relatively low lithospheric thicknesses of $\leq 50 \mathrm{~km}$ depth. In contrast, younger volcanic provinces show a gradual decrease in potential temperature and an increase in lithospheric thickness with time. These results indicate that intermittent plume activity likely plays a significant role in shaping the evolution of cratonic lithosphere. 